\title{
Paediatric Emergencies
}

Edited by J. A. BLACK

Butterworths, London. 1987. 940pp. £70.00.

The second edition of Paediatric Emergencies is a welcome update of an extremely useful publication. It is intended for use as a reference book in general paediatric departments, accident and emergency departments, and neonatal units. An enormous range of material is covered from respiratory arrest to recognition of the rare inborn areas of metabolism. Over 150 pages of data are contained in a separate appendix and this information is of value to all of those involved in the care of children, not just in the emergency situation.

Some of the contents seemed to be of uncertain value for children; for example, the nomogram for evaluation of creatinine clearance is more applicable to adults. Nevertheless, there has been considerable updating in many of the chapters which include such recent phenomena as the ingestion of button batteries and solvent abuse.

There are detailed chapters on child abuse which should be compulsory reading for any doctor examining children in an accident and emergency department. The chapter on sexual abuse in children emphasizes the forensic aspects of diagnosis and gives clear guidelines for dealing with a controversial subject.

There are new chapters on the recognition of brain death, and the management of acute liver failure and of raised intracranial pressure. A number of new authors have also appeared in the second edition.

The editor has made a determined effort to include a number of tropical conditions, together with a section on oral rehydration therapy which are designed to appeal to the overseas' reader. However, some of the conditions are now being imported into the UK with increasing frequency and it is relevant to include such up-to-date information on tropical emergencies within this edition.

\section{S. A. ROBERTS}

Consultant Paediatrician, The Duchess of York Children's Hospital, Manchester, England

\section{Essentials of Emergency Medicine}

By Douglas A. Rund

Appleton-Century-Croft, New Jersey. 1987. 486 pp. £34.80.

Essentials of Emergency Medicine was published in its second edition in January 1987. It was written by Douglas Lund, who is a known author on emergency medicine in the United States of America. This is one of many books available in American literature on emergency medicine and it is described as the book 'written for someone just beginning to participate in the clinical workings of an emergency department'. It is written in 27 chapters, the first being on triage, stabilization and decision making, and the rest dealing with the causation of disease, examination, investigations and management. The chapters start with a general introduction and end up with five or six lines of summary. In this last paragraph, the author has summarized the subject extremely well giving 